\title{
Bacteriological studies of blood, tissue fluid, lymph and lymph nodes in patients with acute dermatolymphangioadenitis (DLA) in course of 'filarial' lymphedema
}

\author{
W.L. Olszewski a,*, S. Jamal b, G. Manokaran c, S. Pani d, V. Kumaraswami e, \\ U. Kubicka a , B. Lukomska a , F.M. Tripathi ${ }^{\text {f }}$, E. Swoboda ${ }^{\mathrm{g}}$, \\ F. Meisel-Mikolajczyk ${ }^{g}$, E. Stelmach ${ }^{\text {a }}$, M. Zaleska ${ }^{\text {a }}$ \\ a The Norwegian Radium Hospital, Oslo, Norway and Department of Surgical Research, Medical Research Center, \\ Polish Academy of Sciences, 5 Pawinski Str., 12106 Warsaw, Poland \\ b Thanjavur Medical College, Thanjavur, India \\ c Apollo Hospitals, Madras, India \\ ${ }^{\mathrm{d}}$ Vector Control Research Center, ICMR, Pondicherry, India \\ e Tuberculosis Research Center, ICMR, Madras, India \\ ${ }^{\mathrm{f}}$ Banaras Hindu University, Varanasi, India \\ g Department of Clinical Bacteriology, Medical Academy, Warsaw, Poland
}

Received 3 July 1998; received in revised form 4 April 1999; accepted 28 April 1999

\begin{abstract}
Filarial lymphedema is complicated by frequent episodes of dermatolymphangioadenitis (DLA). Severe systemic symptoms during attacks of DLA resemble those of septicemia. The question we asked was whether bacterial isolates can be found in the peripheral blood of patients during the episodes of DLA. Out of 100 patients referred to us with 'filarial' lymphedema 14 displayed acute and five subacute symptoms of DLA. All were on admission blood microfilariae negative but had a positive test in the past. Blood bacterial isolates were found in nine cases, four acute $(21 \%)$ and five subacute $(26 \%)$. In 10 acute cases blood cultures were found negative. Six blood isolates belonged to Bacilli, four to Cocci and one was Sarcina. To identify the sites of origin of bacterial dissemination, swabs taken from the calf skin biopsy wounds and tissue fluid, lymph and lymph node specimens were cultured. Swabs from the calf skin biopsy wound contained isolates in nine $(47 \%)$ cases. They were Bacilli in nine, Cocci in three, Acinetobacter and Erwinia in two cases. Tissue fluid was collected from 10 patients and contained Bacilli in four (40\%) and Staphylococci in three (30\%). Lymph was drained in four patients and contained isolates in all samples $(100 \%)$. They were Staphylococcus epidermis, xylosus and aureus, Acinetobacter, Bacillus subtilis and Sarcina. Three lymph nodes were biopsied and contained Staphylococcus chromogenes, xylosus, Enterococcus and Bacillus cereus. In six cases the same phenotypically defined species of bacteria were found in blood and limb tissues or fluids. In the 'control' group
\end{abstract}

\footnotetext{
* Corresponding author.
} 
of patients with lymphedema without acute or subacute changes all blood cultures were negative. Interestingly, swabs from biopsy wound of these patients contained isolates in $80 \%$, tissue fluid in $68 \%$, lymph in $70 \%$ and lymph nodes in $58 \%$ of cases. In healthy controls, tissue fluid did not contain bacteria, and lymph isolates were found only in $12 \%$ of cases. This study demonstrates that patients with acute episodes of DLA reveal bacteriemia in a high percentage of cases. Diversity of blood and tissue bacterial isolates in these patients points to a breakdown of the skin immune barrier in lymphedema and subsequently indiscriminate bacterial colonization of deep tissues and spread to an blood circulation. (C) 1999 Elsevier Science B.V. All rights reserved.

Keywords: Filarial fever; Bacteria; Lymphedema; Lymph

\section{Introduction}

Filarial lymphedema of extremities affects according to the World Health Organization tens of millions of inhabitants of the Third World. The pathomechanism of development of lymphedema remains unclear and treatment of lymph stasis and subsequent tissue fibrosis as well as recurrent inflammatory complications is little effective. The clinical picture of filarial lymphedema of lower extremities caused by Wuchereria bancrofti or Brugia malayi is composed of actually or previously diagnosed microfilaremia, progressive swelling of the limb and recurrent episodes of 'filarial fever' (Pani et al., 1990; Ottesen, 1993). Typical features of 'filarial fever' are malaise, followed by fever and chills, and appearance of acutely swollen, warm and tender skin of the lymphedematous extremity, tenderness along the calf and thigh superficial lymphatics, and enlarged painful inguinal lymph nodes. As the acute process begins in the skin and spreads along the lymphatics to the lymph nodes we call this condition dermatolymphangioadenitis, DLA (Olszewski, 1996a). It is not certain whether DLA in filarial patients is of filarial or bacterial etiology (Ottesen, 1993; Addis et al., 1994; Olszewski and Jamal, 1994; World Health Organization, 1994). It may be produced by intercurrent microbial infections, immunological mechanisms or exposure to infective mosquito bites. Administration of antibiotics evidently sharply reduces the frequency rate of DLA episodes (Olszewski, 1996b). The frequency of episodic DLA is directly related to the stage of lymphedema, and does not depend on the presence or absence of microfilariae (Pani et al., 1995; Olszewski, 1996a). Skin biopsy specimens taken from the lymphedematous extremity during the acute episodes of DLA reveal typical pictures of inflammatory reaction with dense mononuclear cell infiltrates (Olszewski et al., 1993).

The high recurrence rate of DLA may be due to activation of bacterial strains residing in tissues and tissue fluid of the lymphedematous extremity (Olszewski et al., 1997).

The question we asked was whether the acute attacks of DLA are accompanied by bacteriemia and if so which species and strains of bacteria can be isolated from peripheral blood and tissue fluid, lymph and lymph nodes of the lymphedematous extremity. The results were compared with those from patients in the chronic stage of filarial lymphedema without acute symptoms and the control healthy individuals.

\section{Materials and methods}

\subsection{Patients}

One hundred patients with filarial lymphedema, among them 19 with presently acute or recently experienced (within the last 2 weeks) DLA and 81 in a chronic stage without acute symptoms were studied. There were 49 males and 51 females, aged 18-62 years, in stages 0 -IV (Olszewski, 1991a) of chronic lymphedema of lower limbs. In the group with DLA the symptoms were warm, painful and swollen skin of the extremity, tenderness along the vessels in the thigh, in some painful enlarged inguinal lymph nodes, and fever. All patients were on admission blood microfilariae negative but had a positive test in the past. Patients did not receive antibiotics for at least $72 \mathrm{~h}$ prior to the collection of bacteriological specimens. 
The study was approved by the local ethical committees and the WHO/TDR.

\subsection{Healthy controls}

The control groups consisted of 30 healthy subjects (local medical personnel) for control blood cultures, and 16 for cultures of tissue fluid and lymph.

\subsection{Collection of specimens for bacteriological cultures}

All specimens were collected by the same surgeon, under strictly sterile conditions, in the operating room. The results of bacteriological assays were evaluated by two independent bacteriologists. Batches of all instruments and materials used for collection of the specimens were tested for sterility prior to their use in the study.

\subsection{Blood}

Blood samples were taken from cubital vein, after three consecutive desinfections of the skin with alcohol-iodine swabs, into $10 \mathrm{ml}$ syringes. Another needle was then attached to the syringe, and the blood was injected into two Hemoline medium bottles.

\subsection{Skin biopsy wound swab and tissue edema fluid}

Skin was desinfected 3-times with an alcoholiodine swab, allowed to dry, and covered with sterile Tegaderm adhesive foil. An incision was made and a swab placed in the wound for $1 \mathrm{~min}$, which was then transferred to the transport medium. Tissue fluid spontaneously filling the wound was collected in patients with accumulated free fluid (mostly stage II and III) in sterile syringes and $2-5 \mathrm{ml}$ injected into bottles containing Hemoline medium (bioMerieux, France). Control swabs were taken from the desinfected skin and surface of the scalpel prior to the collection of tissue fluid so as to exclude these potential sources of contamination.

\subsection{Lymph}

Through the above described incision, a superficial lymph vessel draining the skin of the foot and lower part of calf was exposed and cannulated in patients with patent (nonobliterated) lymphatics with a sterile siliconized polyethylene cannula (1.6 O.D, 1.1 I.D) (Adams Clay, USA) (Olszewski, 1991b). The cannula was inserted into the vessel in a retrograde fashion and lymph was collected in sterile test-tubes containing $0.1 \mathrm{ml}$ of heparin (Novo, Denmark) without preservative. The collection period lasted for 6-24 h. Five millilitres of lymph were transferred to Hemoline media.

\subsection{Lymph node}

Briefly, a wet swab was taken from the skin of the inguinal fossa region. Then, skin was desinfected with alcohol-iodine solution, dried, and covered with sterile Tegaderm adhesive foil. Incison was made and another swab taken from the wound. A $5 \times 5 \mathrm{~mm}$ biopsy of lymph node was taken, placed in transport medium, and homogenized prior to culture.

\subsection{Culture media}

The following media were used: Hemoline liquid medium (bioMerieux, France), Columbia Blood Agar Base enriched with 5\% sterile defibrinated sheep blood, Mac Conkey's agar, Chapman's agar, Sabouraud's agar (Malt agar) and BHI (Brain Heart Infusion) (all Difco, USA).

\subsection{Identification of bacterial strains}

All specimens were incubated at $37^{\circ} \mathrm{C}$ and examined at 24 and $48 \mathrm{~h}$ for aerobic and anaerobic bacterial growth. In cases there was no anaerobic growth, further cultures for anaerobic growth were established. Tissue fluid, lymph and venous blood were placed in Hemoline medium and lymph nodes in BHI medium and examined every day for 14 days. Isolates were identified by standard procedures using the Api identification system (bioMerieux, France). The aerobic cocci of the Micrococcaccae family were identified using 
the Api-Staph system. Bacteria of Streptococcaccae family were identified with Api 20 Strep. Gram-negative rods were identified using Api 20E. Gram-positive spore-forming bacilli-Bacillus spp. were identified by evaluating the fermentation of sugars or polyalcohols.

The sensitivity of isolated bacterial strains to antibiotics was examined using the ATB system (bioMerieux, France).

\section{Results}

\subsection{Prevalence of isolates in patients with acute or recently experienced $D L A$}

Blood isolates were found in nine out of 19 patients (47\%), four with severe DLA and five with recent acute episode (Table 1). Ten patients with acute symptoms had negative blood cultures. Among the isolates Bacilli were cultured from six, Cocci from four and Sarcina from one specimens (Table 2). Swabs from skin biopsy wounds revealed presence of isolates in nine cases (47\%) with Bacilli in nine, Cocci in three, cinetobacter and Erwinia in two specimens. Tissue fluid was available only in patients with accumulation of free fluid under the dermis and in subcutis and lymph in those with non-obstructed lymphatics technicaly suitable for cannulation. Tissue fluid obtained from 10 patients contained isolates in six $(60 \%)$. Four strains of Bacilli and three of Staphy- locci were found. Lymph samples were collected from four patients and contained bacteria in all $(100 \%)$. There were four strains of Cocci and one of Bacilli, Acinobacter and Sarcina. Lymph node biopsy specimens were obtained from three patients and contained bacteria in all $(100 \%)$, with two strains of Cocci, one Enterococcus and three of Bacilli. In six patients isolates of the phenotypically same species or strains and sensitivity to antibiotics were found in blood and limb tissues or fluids. Staphylococci with identical antibiogrammes (sensitivity to penicilin G, oxacillin, kanamycin, tobramycin, gentamycine, minocycline, erythromycin, lincomycin, quinolones 2 nd yen, cotrimoxazole, methicillin) were found in blood and tissue fluid, lymph or lymph nodes in two, Bacilli in three, and Micrococcus in 1 patient.

\subsection{Prevalence of isolates in patients in chronic stage without recent episodes of DLA}

Blood cultures were performed in 71 patients and in all cases were found negative (Table 1). Swabs from skin biopsy wound contained bacteria in $80 \%$, tissue fluid in $68 \%$, lymph in $70 \%$ and lymph nodes in 58\% of specimens (Table 1). Bacilli were cultured from skin biopsy wound swabs in $77 \%$, tissue fluid in $57 \%$, lymph in $61 \%$, lymph node in $9 \%$ of specimens and Cocci in 23 , 43,39 and $91 \%$, respectively.

\section{Table 1}

Prevalence of bacterial isolates from specimens obtained from swollen limbs and blood of 100 patients with 'filarial' lymphedema during the acute episode of DLA and in the chronic stage

\begin{tabular}{|c|c|c|c|c|c|c|}
\hline \multirow[t]{3}{*}{ Specimen } & \multicolumn{6}{|c|}{ Number of specimens } \\
\hline & \multicolumn{3}{|c|}{ Acute DLA $(n=19)$} & \multicolumn{3}{|c|}{ Chronic stage $(n=81)$} \\
\hline & Total & Positive & \% Positive & Total & Positive & $\%$ Positive \\
\hline Biopsy wound & 19 & 9 & 47 & 68 & 55 & 80 \\
\hline Lymph & 3 & 3 & 100 & 17 & 7 & 58 \\
\hline Blood & 19 & 9 & 47 & 71 & 0 & 0 \\
\hline
\end{tabular}


Table 2

Bacterial isolates from blood, tissues and fluids of limbs with filarial lymphedema during or immediately after the acute episode of dermatolymphangioadenitis (DLA)

\begin{tabular}{|c|c|c|c|c|c|c|}
\hline \multirow[t]{2}{*}{ Patient } & \multirow{2}{*}{$\begin{array}{l}\text { Stage of } \\
\text { lymphedema }\end{array}$} & \multicolumn{5}{|c|}{ Origin of bacterial isolates } \\
\hline & & Blood & Biopsy wound & Tissue fluid & Lymph & Lymph node \\
\hline \multicolumn{7}{|c|}{ Acute episode } \\
\hline 1 & II & B. pumilis & $0^{\mathrm{a}}$ & $\mathrm{ND}^{\mathrm{b}}$ & ND & ND \\
\hline 3 & III/IV & Staph. xylosus & 0 & ND & ND & Staph. xylosus \\
\hline 4 & II & $\begin{array}{l}\text { B. cereus } \\
\text { Aerococcus } \\
\text { Staph. lentus }\end{array}$ & $\begin{array}{l}\text { B. cereus } \\
\text { Erwinia }\end{array}$ & ND & ND & ND \\
\hline 5 & II/III & 0 & 0 & ND & Staph. aureus & ND \\
\hline 7 & IV & 0 & $\begin{array}{l}\text { B. subtil } \\
\text { Acinetobacter }\end{array}$ & 0 & ND & B. cereus \\
\hline 8 & III & 0 & 0 & ND & ND & B. cereus \\
\hline 9 & III/IV & 0 & $\begin{array}{l}\text { Microcccus lu- } \\
\text { teus }\end{array}$ & 0 & ND & ND \\
\hline 10 & II & 0 & B. subtilis & 0 & ND & ND \\
\hline 11 & II & 0 & $\begin{array}{l}\text { B. saprophiticus } \\
\text { Micrococ spp. } \\
\text { B. badius }\end{array}$ & ND & ND & ND \\
\hline 12 & III & 0 & 0 & $\begin{array}{l}\text { B. coagulans } \\
\text { B. subtilis } \\
\text { Staph. hominis }\end{array}$ & ND & ND \\
\hline 17 & III & Micrococ. spp. & 0 & B. firmus & ND & ND \\
\hline 18 & $\mathrm{II} / \mathrm{III}$ & B. lentus & B. coagulans & ND & $\begin{array}{l}\text { Staph. xylosus } \\
\text { Staph. epidermidis } \\
\text { B. subtilis }\end{array}$ & $\mathrm{N}$ \\
\hline 19 & II/III & Sarcina & 0 & ND & Sarcina & ND \\
\hline
\end{tabular}

a 0 , no isolates detected.

${ }^{\mathrm{b}} \mathrm{ND}$, not done; no free fluid in biopsy wound; no indications for lymphatic cannulation and lymph node biopsy.

\subsection{Prevalence of isolates in healthy inividuals}

In healthy controls, blood and wound swab cultures were negative in all cases. In two out of 16 lymph samples $(12 \%)$ bacterial isolates were found. These were Micrococcus spp. and Acinetobacter.

\subsection{Sensitivity of bacterial isolates to antibiotics}

Bacilli from all sources were found most susceptible to gentamycin, tetracycline, rifampicin, vancomycin, kanamycin and cotrimoxazol, and less to penicillin. Cocci revealed a similar qualitative pattern of sensitivity to the tested antibiotics. 
There were no differences in sensitivity to antibiotics of strains obtained from the acute DLA and chronic stage groups.

\section{Discussion}

This study revealed a high prevalence of bacterial isolates from peripheral blood in patients with acute or recently experienced DLA episodes. In patients with lymphedema without DLA recurrency, blood cultures were negative, although in both groups, with or without acute DLA episodes the tissue fluid, lymph and lymph nodes of the lymphedematous extremities contained bacteria in around $70 \%$ of investigated cases. In the healthy subjects tissue fluid swabs were found sterile in all cases and lymph samples revealed presence of bacteria only in two out of 16 cases $(12 \%)$. Here we should also refer to our European group of 40 volunteers, in whom all leg lymph samples collected over days remained sterile (unpublished).

Our concept is that lymph stasis in limbs of Indian patients with filarial lymphedema and exposure to a highly contaminated environment predispose to bacterial colonization of skin and penetration of microbes to deeper tissues and the lymphatics of the extremities. Moreover, the colonizing bacteria may, under certain conditions (skin microtrauma, insect bite), become activated and find their way from tissues and fluids of the limb to the blood circulation. The similarities in phenotypes and sensitivity to antibiotics of blood and tissue fluid, lymph and lymph node isolates in some cases point to the possibility of such a pathway of bacterial spread. Similarities of the bacterial genome would certainly be more objective and allow to draw conclusions.

The question arises as to whether the isolates, usually residents of normal skin surface, could be considered as pathogens, once they have penetrated epidermis and lodged in dermis, subcutis, lymphatics and lymph nodes. Most of literature information on this problem originates from studies on pathogens isolated in cases of erysipelas and cellulitis, where coagulase-positive Staphylococci, Streptococci, and anaerobes predominate (Hook et al., 1986; Kielhoer et al., 1988; Newell and Norden, 1988 Duvanel et al., 1989; Sigurdsson and Gudmundsson, 1989). The strains as coagulase-negative $S$. aureus, Streptococcus beta group A,B,D, S. epidermidis, Corynebacterium spp., Bacillus spp., and Prioprionibacterium spp. are clasically considered to be contaminants (Duvanel et al., 1989; Marples et al., 1990). However, these strains may become virulent in the immunocompromized tissues. The tissues with chronic lymph stasis are immunocompromized due to the impaired transport away of bacterial, viral and other antigens penetrating the epidermis. There is also inhibition of the process of recirculation and decreased capillary filtration of immune proteins (Olszewski and Engeset, 1990). Such tissues may easily be colonized by bacteria physiologically residing on the epidermis and penetrating it during microinjuries of the foot and calf. Once in the tissues, bacteria may evoke inflammatory reaction, which could be naturally controlled in a normal but not in a lymphedematous tissue. The strains considered before as saprophites become virulent due to the changes in their environment. This applies to $S$. epidermidis which can cause sepsis and shock (Zierdt, 1983; Hedin, 1993; Burchard et al., 1984). Coagulase-negative Staphylococci and Bacterioides can be a cause of bacteriemia during skin surgery (Carmichael et al., 1993). The Bacilli are significant residents of skin depending on individual differences in skin nutrients, microclimate, and inhibiting substances of host or resident flora origin (Bibel et al., 1978). They were found on the toe webs and calf skin of all Indian patients. Although not much is known about their virulence in tissues, they can produce major systemic disturbances (Bibel et al., 1978). Bacillus species have been documented as causes of meningitis, septicemia, osteomyelitis and eye infections. Recently, bacterial products of Staphylococci coined superantigens have been shown to be responsible for recurrent skin inflammation (Leung et al., 1993; McFadden, 1995; Skov, 1995). The superantigens activate T-cells, and cause cytokine release and mast cell degranulation. An unanswered question remains which factors may provoke the existing flora to become virulent. 
The basic question arises whether the identified microorganisms could be responsible for the acute episodes of DLA. Strong evidence supporting this view comes from the positive results of blood cultures during the attacks of DLA. Positive blood cultures were reported by Hook in acute cutaneous cellulitis (Hook et al., 1986). A low number of cases with acute DLA and positive blood cultures does not allow to draw firm conclusions. However, since blood cultures were negative in all cases of chronic lymphedema and positive only during acute episodes of DLA, the concept of cultured coagulase-negative staphylococci and bacilli as responsible for acute skin changes and bacteriemia seems to find its justification. Local acute inflammatory changes either preceded or accompanied detected bacteriemia. Differentiation of the phenotypes of certain bacterial strains within a species may be difficult. This applies among others to bacilli and also some coagulase-negative staphylococci. Thus, from the clinical point of view of most importance remains whether bacteriemia is caused by bacilli or saprophite stapylococci in general, not focusing upon their subtypes. More insight into the problem of identity of skin and blood cultured bacteria would give application of genetic studies of strains. Interestingly, in our recent studies of genomic DNA, we found identical restrictive DNA pattern of $S$. epidermidis obtained from the toe skin and lymph nodes (unpublished). Chronic bacterial colonization of deep tissues in obstructive lymphedema has been proved (Olszewski et al., 1997), however, what causes sudden proliferation and spread of microorganisms remains still unknown. We observed recurrent episodes of acute DLA mostly after physical injury of lymphedematous skin (superficial abrasion, longdistance marching).

Taken together, our studies clearly show that foot and calf skin and subcutaneous tissue, tissue fluid, lymph and lymph nodes are colonized by bacteria which are occasionally spread to the blood circulation. The systemic symptoms observed during acute DLA episode may depend on the presence of bacteria in blood, however, in some cases with acute changes in the limb bacteriemia could not be documented. Diversity of blood and tissue bacterial isolates points to the breakdown of the skin immune barrier in the lymphedematous limbs and subsequently indiscrimate colonization of deep tissues and spread to blood circulation. The question of what stimulates tissue-residing bacteria to proliferate and to evoke local and systemic reactions in patients with filarial lymphedema remains unclear.

\section{Acknowledgements}

This investigation received financial support from UNDP/World Bank/WHO Special Programme for Research and Training in Tropical Diseases.

\section{References}

Addis, D.G., et al., 1994. 'Filarial' adenolymphangitis without filarial infection. New Engl. Lancet 343, 597-600.

Bibel, D.J., et al., 1978. Survival of Bacillus licheniformis on human skin. Appl. Envir. Microbiol. 35, 1128-1135.

Burchard, K.W., Minor, L.B., et al., 1984. Staphylococcus epidermidis sepsis in surgical patients. Arch. Surg. 119, 96-100.

Carmichael, A.J., Flanagan, P.G., et al., 1993. The incidence of bacteremia in skin surgery. Br. J. Dermatol. 129 Suppl. 42, 49.

Duvanel, Th., Auckenthaler, R., et al., 1989. Quantitative cultures of biopsy specimens from cutaneous cellulitis. Arch. Int. Med., 149, 293-296.

Hedin, G., 1993. Staphylococcus epidermidis-hospital epidemiology and the detection of methicillin resistance. Scand. J. Infect. Dis., 90 (Suppl.), 23-25

Hook, E.W., Hooton, Th. et al., 1986. Microbiologic evaluation of cutaneous cellulitis in adults. Arch. Int. Med., 146, 295-297.

Kielhoer, M.A., et al., 1988. Influence of underlying disease process on the utility of cellulitis needle aspirates. Arch. Int. Med. 148, 2451-2452.

Leung, D.Y.M., Harbeck, R., et al., 1993. Presence of IgE antibodies to Staphylococcal exotoxins on the skin of patients with atopic dermatitis. J. Clin. Invest. 92, 13741380 .

Marples, R.R., Richardson, J.F., Newton, F.E., 1990. Staphylococci as part of the normal flora of human skin. J. Appl. Bacteriol. 19, 93S-99S.

McFadden, J.P., et al., 1995. Superantigenic exotoxin-secreting potential of Staphylococci isolated from atopic eczematous skin. Br. J. Dermatol. 128, 631-632. 
Newell, P.M., Norden, C.W., 1988. Value of needle aspiration in bacteriologic diagnosis of cellulitis in adults. J. Clin. Microbiol. 26, 401-404.

Olszewski, W.L., Engeset, A., et al., 1990. Immune cells in peripheral lymph and skin of patients with obstructive lymphedema. Lymphology 23, 23-33.

Olszewski, W.L., 1991a. Lymph Stasis: Pathophysiology, Diagnosis and Therapy. CRC Press, Boca Raton, FL, pp. 349-367.

Olszewski, W.L., 1991b. Lymph Stasis: Pathophysiology, Diagnosis and Therapy. CRC Press, Boca Raton, FL, pp. 609-615.

Olszewski, W.L., Jamal, S., et al., 1993. Skin changes in filarial and non-filarial lymphedema of the lower extermities. Trop. Med. Parasitol. 44, 40-44.

Olszewski, W.L., Jamal, S., 1994. Skin bacterial factor in progression of filarial lymphedema. Lymphology 27, 148149.

Olszewski, W.L., 1996a. Recurrent bacterial dermatolymphangioadenits (DLA) is responsible for progression of lymphedema. Lymphology 29 Suppl. 24, 100-104.

Olszewski, W.L., 1996b. Episodic dermatolymphangioadenitis (DLA) in patients with lymphedema of lower extremities and benzathine penicillin administration. Lymphology 29, 230-235.

Olszewski, W.L., Jamal, S., et al., 1997. Bacteriologic studies of skin, tissue fluid, lymph nodes in patients with filarial lymphedema. Am. J. Trop. Med. Hyg. 57, 7-15.

Ottesen, E.A., 1993. Filarial infections. Infect. Dis. Clin. Am. 7, 619-633.

Pani, S.P., Krishnamoorthy, K., et al., 1990. Clinical manifestations in malayan filariasis infection with special reference to lymphoedema grading. Indian J. Med. Res. 91, 200207.

Pani, S., Yuvaraj, J., et al., 1995. Episodic adenolymphangitis and lymphoedema in patients with bancroftian filariasis. Trans. Royal Soc. Trop. Med. Hyg. 89, 211-214.

Sigurdsson, A.F., Gudmundsson, S., 1989. The etiology of bacterial cellulitis as determined by fine-needle aspiration. Scand. J. Infect. Dis. 21, 537-542.

Skov, L., 1995. Superantigens. Arch Dermatol. 131, 829-832.

Zierdt, Ch. H., 1983. Evidence for transient Staphylococcus epidermidis bacteremia in patients and in healthy humans. J. Clin. Microbiol., 17, 628-630.

World Health Organization, 1994. Lymphatic filariasis, infection \& disease. Geneva. WHO/TDR. 